\title{
The new divide: how a scientist-gone-filmmaker thinks Hollywood can save science
}

Book

\section{Reviewed by}

Abstract

Keywords
OLSON, R. (2015). Houston, we have a narrative: Why science needs story. CHICAGO, U.S.A.: UNIVERSITY OF CHICAGO PRESS

\section{Victoria Gant}

Scientist-turned-filmmaker Randy Olson makes a bold claim: scientists cannot adequately explain their own work. He attributes all of the issues facing science communication today - false positives, an uninterested public, and unapproved grant proposals - to scientists' lack of narrative intuition. Rather than turn to the humanities for help, Olson suggests scientists learn from the true masters of storytelling - Hollywood filmmakers. His latest book examines the age-old divide between science and the humanities, as well as the new adversarial relationship between science and film, which he says can save science.

Scholarly communication; Science and media; Science writing

My undergraduate education in the humanities was spent at a primarily scientific institution. What I experienced in those years was a divide beyond what C. P. Snow describes in The Two Cultures. A book that, in 1959, predicted the widening split between the sciences and humanities, The Two Cultures was the first time anyone had described the problem with learned scholars embracing the idea of not understanding another school. But what I witnessed among students of the sciences was contempt for even the mere idea of understanding the humanities. None of the biology, chemistry, or engineering students I met cared to learn anything about conveying their ideas, particularly through writing. This sort of disregard for the importance of writing is described in Randy Olson's Houston, We Have a Narrative: Why Science Needs Story.

Randy Olson was once one of those science students, contemptuous of the humanities. It took a career change for him to realize why writing is important. After earning tenure as a professor of marine biology, he abandoned the ivory tower for Hollywood, where he hoped to create films about his work as a scientist. However, he quickly realized that the narrative tools he needed as a filmmaker were skipped over in his undergraduate education.

Houston, We Have a Narrative is his most recent and most practical book on teaching scientists how - and why - to write narratively about their work. In his first few 
chapters, he bases his argument on his experience with narrative in Hollywood. He focuses the rest of the book on teaching readers how to use the narrative structure.

Olson begins with a point he reiterates throughout his book — scientists do not know how to tell stories. Nor do they know what a story is. This, Olson boldly argues, is the source of every single problem science communication has faced for the last century. False positives, an uninterested public, and unapproved grant proposals can all be attributed to scientists' lack of narrative intuition.

Olson explains the lack of narrative intuition with a series of formulas. Scientists talk and write about their work with an "AAA" formula - and, and, and. These "stories" are nothing but a list of details and facts, and with no climax or conclusion, they are not stories at all. Though a presentation, journal article, or book written as an AAA may be packed with important information, readers retain very little of it.

In contrast, the "ABT" formula - and, but, therefore - allows for the audience to learn the information the scientist presents. This ABT is the narrative core of a story. In short, something happens, and something else happens, but there is a conflict, and therefore resolution is necessary. Olson uses the ABT in the titles of his first three chapters, writing: "Science is stuck in a narrative world and the humanities ought to help. But the humanities are useless for this, therefore Hollywood to the rescue."

Olson relies on the narrative intuition of Hollywood filmmakers rather than humanities scholars for his argument and examples of narrative success. Not only are the most popular and successful movies ABTs, he says, but so are the most impactful research studies. Watson and Crick's 1953 research article is the most notable example in science.

But Olson is careful with his claims. He makes a point of mentioning the ethical issues surrounding Watson and Crick's work every time he writes about them. This is because Olson has been accused of shirking ethics himself, and he repeatedly denies the charge that he is advocating "bending the science." That is, he emphasizes that he is not asking scientists to lie about their research so it fits in with a narrative formula. Scientists' stories are already interesting — they simply need to find which parts of their narrative deserve to be highlighted. This is a process he explains with several more formulas for effective storytelling, and counters claims that formulas make for boring stories, writing: "The problem of material being overly formulaic arises when the material itself is devoid of content."

Olson takes his own advice by using his formulas to create a book that is easy to understand. The only confusing thing about it is its intended audience. Whether he means to target scientists or their students, it doesn't quite work. For science students, this book provides insight into using narrative storytelling independently. However, in this regard, Olson's book resembles the AAA format he criticizes. That is, the book is a series of interesting bits of information that, without the institutional structure to implement narrative storytelling in the sciences, will simply be forgotten. But Olson does have a suggestion for creating this institutional structure. 
For his scientist readers, Olson suggests something called "story circles." To shift the paradigm of science writing in favor of a narrative culture, scientific institutions should host these story circles, small gatherings of scientists where they can regularly learn about and discuss narrative. However, the practicality of Olson's story circles suffers. By relying on the narrative knowledge of Hollywood filmmakers rather than humanities scholars, it is unclear how these story circles are supposed to work - does he intend to house a filmmaker at every scientific institution to teach scientists how to write?

Houston, We Have a Narrative offers a novel approach to solving science communication's most pertinent issues by integrating the profession of filmmaking. Randy Olson makes a valuable, modern day contribution to our understanding of the split between science and the humanities as described in C. P. Snow's work decades prior. But rather than mending the divide as Snow suggests, Olson drives a larger wedge between the two cultures. While filmmakers may have been the source of the narrative tools Olson describes, the most practical way to create a narrative culture would be through the use of existing structures. Housed at nearly every university in the nation, communication scholars are dedicated to understanding the most effective ways to convey information. The most practical way to create a narrative culture, then, may not involve English professors, but it could certainly include communication scholars.

References

Snow, C. P. (1959). The two cultures and the scientific revolution. Cambridge, U.K.: Cambridge University Press.

Watson, J. D. and Crick, F. H. C. (1953). 'Molecular Structure of Nucleic Acids: A Structure for Deoxyribose Nucleic Acid'. Nature 171 (4356), pp. 737-738. DOI: 10.1038/171737a0.

Author

Victoria Gant is a science communication scholar at Drexel University. E-mail: vpg25@drexel.edu.

How to cite

Gant, V. (2016). 'The new divide: how a scientist-gone-filmmaker thinks Hollywood can save science'. JCOM 15 (05), R01.

This article is licensed under the terms of the Creative Commons Attribution - NonCommercial NoDerivativeWorks 4.0 License.

ISSN 1824 - 2049. Published by SISSA Medialab. http:/ /jcom.sissa.it/. 